\title{
The effect of oxygen in the photocatalytic oxidation pathways of
}

\section{perfluorooctanoic acid}

Maurizio Sansotera $^{\mathrm{a}, \mathrm{b}}$, Federico Persico ${ }^{\mathrm{a}}$, Valentina Rizzi ${ }^{\mathrm{a}}$, Walter Panzeri ${ }^{\mathrm{c}}$, Carlo Pirola ${ }^{\mathrm{b}, \mathrm{d}}$, Claudia

$$
\text { L. Bianchi }{ }^{\mathrm{b}, \mathrm{d}} \text {, Andrea Mele }{ }^{\mathrm{a}, \mathrm{b}} \text {, Walter Navarrini }{ }^{\mathrm{a}, \mathrm{b}, *}
$$

a Dipartimento di Chimica, Materiali e Ingegneria Chimica “Giulio Natta”, Politecnico di Milano, Via Mancinelli 7, 20131, Milano, Italy

${ }^{b}$ Consorzio Interuniversitario Nazionale per la Scienza e Tecnologia dei Materiali (INSTM), Via G. Giusti 9, 50121, Firenze, Italy

${ }^{c}$ C.N.R. - Consiglio Nazionale delle Ricerche, Istituto di Chimica del Riconoscimento Molecolare, Sezione "U.O.S. Milano Politecnico", Via Mancinelli 7, 20131, Milano, Italy

${ }^{d}$ Dipartimento di Chimica, Università degli Studi di Milano, Via Golgi 19, 20133, Milano, Italy

* Corresponding author. Tel: +39.02.2399.3029; Fax: +39.02.2399.3180; Email Address:

$$
\text { walter.navarrini@polimi.it }
$$

\begin{abstract}
The influence of oxygen in the photocatalytic oxidation of perfluorooctanoic acid (PFOA) promoted by a commercial nano-sized titanium dioxide was studied by testing the reaction in different conditions: static air, oxygen flux, nitrogen flux and pre-saturated nitrogen flux. The reaction was monitored by Total Organic Carbon (TOC) analysis and Ionic Chromatography (IC). Shorter chain perfluorocarboxylic acids (PFCAs; $\mathrm{C}_{\mathrm{n}}, \mathrm{n}=1-7$ ) intermediate degradation products were quantitatively determined by High-Performance Liquid Chromatography combined with Mass Spectrometry (HPLC-MS) analysis. The presence of shorter chain PFCAs in solution was also monitored by ${ }^{19}$ F-NMR. The experimental findings are in agreement with two major oxidative
\end{abstract}


pathways: $C_{n} \rightarrow C_{n-1}$ photo-redox and $\beta$-scissions routes mediated by $\mathrm{COF}_{2}$ elimination. Depending on the experimental conditions, the mutually operating mechanisms could be unbalanced up to the complete predominance of one pathway over the other. In particular, the existence of the $\beta$-scissions route with $\mathrm{COF}_{2}$ elimination was corroborated by the isolation and characterization of carbonyl difluoride, a predicted fluorinated decomposition by-product.

Keywords: PFOA, Oxidation, Titanium dioxide, Photocatalysis, Carbonyl difluoride

\section{Introduction}

PFOA and its salts are exogenous very stable perfluorinated surfactants, utilized till now for the preparation of the majority of fluoropolymers that are worldwide employed in thousands of everyday life essential applications, such as manufacturing, aerospace, automotive, electronics, semiconductors and textile [1]. PFOA UV stability and high surface-active effects are due to its completely perfluorinated structure [2-4]. However, perfluorocarboxylic acids (PFCAs) are nowadays source of great concern due to their proved persistence in the global abiotic and biotic environment, including food and humans [5-7]. These compounds, in fact, are among the most widely diffused fluorinated surfactants into waste streams [8-10].

The 2015 is the deadline for the complete phase out of perfluorooctanoic acid; this phase out plane was launched in the PFOA Stewardship Program by US-EPA and by eight major companies in 2006 [1]. As a direct consequence of this program, the fluoropolymer industry has been forced to develop new environmentally friendly surfactants suitable for emulsion polymerization. In addition, from that moment on, many important research studies on PFOA substitutes and related materials appeared in the specialized literature [11-17]. Furthermore, due to recent findings on the extreme difficulty to decompose PFOA by using standard methodologies, new and effective degradation techniques like electrochemical [18], modified Fenton reagent [19], sonochemical [20], plasma [21], microwave [22], photochemical [23,24] and photocatalytic methods [25-29] have been studied 
and published. In addition extensive technological reviews are also available in the literature [3032].

In this study, we analyzed the influence of oxygen in PFOA photocatalytic oxidation induced by UV-activated $\mathrm{TiO}_{2}$. Semiconductors, in particular $\mathrm{TiO}_{2}$, are characterized by an electronic band structure in which electrons from the valence band $\left(\mathrm{V}_{\mathrm{b}}\right)$ are promoted to the conductive band $\left(\mathrm{C}_{\mathrm{b}}\right)$ with the simultaneous generation of positively charged holes $\left(\mathrm{h}^{+}\right)$in the $\mathrm{V}_{\mathrm{b}}$ by the absorption of a photon flux of energy equal or higher to the bandgap energy. The electron-hole pairs can recombine in a few nanoseconds, or they can be trapped in surface states where they can react with donor or acceptor species adsorbed on the photocatalyst surface [33]. Interface redox reactions involving both excited electrons and photogenerated holes must compete effectively with the recombination processes of the electron-hole pairs $[34,35]$. In the presence of water and oxygen, hydroxyl radicals $\cdot \mathrm{OH}$ and superoxide ions $\mathrm{O}_{2}^{-} \cdot$ are generated [36]. These intermediates are strong oxidizing species able to mineralize organic compounds [37,38]. However, an extensive debate on the oxidative pathway of PFOA exists nowadays, because it has been demonstrated that $\cdot \mathrm{OH}$ radicals generated by Fenton reagent are not very effective in the PFOA mineralization $[30,39]$ and that $\mathrm{Ti}^{\cdot \mathrm{IV}} \mathrm{OH}^{+}$can take an active part in the mineralization reaction $[27,40,41]$.

Despite the numerous studies on PFOA oxidation, at the moment a complete rationalization of the decomposition pathways is not available. The interpretation of experimental findings, as well as $a$ priori calculations reported in the literature, are often in apparent contradiction $[19,26,30]$ and provide an incomplete interpretation of the PFOA oxidation mechanism [25] or, in some cases, the experimental findings are complementary $[18,21]$. The intent of this work is to give our contribution to the understanding of this intriguing reaction. In particular, we focused on the influence of oxygen in the photocatalytic oxidation of PFOA induced by $\mathrm{UV}$-activated $\mathrm{TiO}_{2}$ and we obtained that, differently from static conditions, a continuous oxygen feeding enhanced the decomposition of PFOA till its mineralization. On the contrary, PFOA photooxidation was hindered in a nitrogensaturated reaction environment. 
The use of oxygen excess directed the PFOA decomposition through a reaction pathway involving the formation of oxygen-centered perfluorinated radicals as major intermediates. As already hypothesized, the perfluorinated oxyradicals preferentially followed a $\beta$-scission route by releasing carbonyl difluoride, $\mathrm{COF}_{2}$, as a specific by-product, which can be hardly isolated due to its rapid hydrolysis in aqueous media [42]. Carbonyl difluoride is an important intermediate for the industrial synthesis of key fluorinated monomers and it is essential in the preparation of fluoroplastics and perfluororubbers [43-45]. In this work, we firstly report that the intermediate $\mathrm{COF}_{2}$ can be isolated in pure form and in good selectivity by performing the photocatalytic oxidation of PFOA in a suitable perfluorinated aprotic solvent, instead of water. Moreover, in these conditions the catalyst deactivation due to fluoride ions is mostly inhibited [27]. As often happens, a more complete understanding of a reaction mechanism gives more options in the utility of the reaction under study [46,47]. In particular, in the photocatalytic oxidation of PFOA a new chemical route has been identified for the synthesis of carbonyl difluoride, $\mathrm{COF}_{2}$.

\section{Materials and methods}

\subsection{Materials}

Perfluorooctanoic acid (purity 96\% - from Sigma Aldrich ${ }^{\circledR}$ ) was used as received. PFOA is soluble in water $(9.5 \mathrm{~g} / \mathrm{L})$ and its critical micelle concentration $(\mathrm{CMC})$ is $7.80 \cdot 10^{-3} \mathrm{~mol} / \mathrm{L}$ at $25^{\circ} \mathrm{C}$ [48]. Titanium dioxide P-25 (75\% Anatase, 25\% Rutile) was supplied by Evonik ${ }^{\circledR}$ and it was tested as a titanium-based photocatalyst. The coexistence of anatase and rutile in commercial P-25 causes the catalyst photoactivity to be enhanced if compared to pure anatase [49]. The presence of small rutile crystallites, in fact, creates a structure characterized by a more stable charge separation, slowing recombination reactions on anatase; moreover, the smaller band gap of rutile extends the useful range of photoactivity into the visible region [49]. Water was purified by using an Elga Option 3 deionizer and it was used to prepare PFOA solutions for the different kinetic tests. Milli-Q water was employed for ion chromatography. HPLC-MS analyses were carried out by using as an eluting 
phase a mixture of methanol (CHROMASOLV ${ }^{\circledR}$, for HPLC, $\geq 99.9 \%$ - from Sigma Aldrich ${ }^{\circledR}$ ) and 2 $\mathrm{mM}$ aqueous ammonium acetate solution. The evaluation of $\mathrm{COF}_{2}$ formation during PFOA abatement was specifically monitored by degrading a solution of PFOA in Galden ${ }^{\circledR}$ HT-170 (from Solvay Specialty Polymers), a PFPE-based solvent with boiling point of $170^{\circ} \mathrm{C}$ and formula as follows: $\mathrm{CF}_{3} \mathrm{O}\left(\mathrm{CF}_{2} \mathrm{CF}\left(\mathrm{CF}_{3}\right) \mathrm{O}\right)_{p}\left(\mathrm{CF}_{2} \mathrm{O}\right)_{n} \mathrm{CF}_{3}(\mathrm{AMW}=760)$.

\subsection{Photocatalysis}

The photocatalytic apparatus was a $1 \mathrm{~L}$ glass stirred reactor equipped with an iron halogenide UV lamp (500 W, Jelosil ${ }^{\circledR}$ HG500) emitting light at wavelengths of 315-400 nm and able to irradiate the reactor with a specific power of $75 \mathrm{~W} / \mathrm{m}^{2}$. The UV lamp was placed beside the reactor, which was cooled with water at a temperature of $30.0 \pm 0.5^{\circ} \mathrm{C}$ [27]. Titanium dioxide was introduced in the reactor at the beginning of each test $(0.66 \mathrm{~g} / \mathrm{L})$ [27]. The variation of the surfactant concentration in solution was monitored by Total Organic Carbon (TOC) analysis and Ionic Chromatography [27]. The PFOA initial concentration $\left([\mathrm{PFOA}]_{0}=4 \mathrm{mM}\right)$ was maintained lower than its $\mathrm{CMC}(7.8 \mathrm{mM}$ [48]) in order to avoid the formation of emulsions that would reduce the $\mathrm{TiO}_{2}$-promoted photodegradation rates $[27,28]$. Moreover, the PFOA initial concentration was high enough to allow the detection of the degradation intermediates, even at very low concentrations. Each kinetic test was repeated three times in order to evaluate the error extent and realized by collecting samples (10 $\mathrm{ml}$ ) of the reaction mixture at predetermined reaction times. Samples were centrifuged and filtered through a $0.45 \mu \mathrm{m}$ polycarbonate membrane in order to separate the $\mathrm{TiO}_{2}$ powder from the solution. Photocatalytic process could be commonly described in terms of a modified LangmuirHinshelwood (L-H) model, which has been successfully used for heterogeneous photocatalytic degradation by determining the relationship between the apparent first-order rate constant and the initial content of the organic substrate $[50,51]$ :

$$
r=-\frac{d C}{d t}=\frac{k_{r} K_{S} C}{1+K_{S} C_{0}}=k_{a p p} C
$$


In Equation 1, $r$ is the reaction rate, $C$ is the pollutant concentration in solution, $C_{0}$ is the initial organic content, $k_{r}$ is the reaction rate constant, $K_{S}$ is the adsorption rate constant, $t$ is the time and $k_{\text {app }}$ the apparent first-order rate constant. In the original L-H model the rate constant $k_{r}$ and the adsorption constant $K_{S}$ are independent of light intensity and $K_{S}$ should not vary with the light intensity because it represents the adsorptive affinity of a substrate on the catalyst surface. Differently, in the modified L-H model the light intensity can affect both kinetic constants $\left(k_{r}, K_{S}\right)$, as reported in the literature $[50,51]$.

The effects on PFOA photocatalytic oxidation due to both oxygen excess and deficiency in the reaction environment were evaluated by running and comparing the results of specific kinetic tests; in particular, PFOA degradation trends were monitored in atmospheric conditions (Air test), in the presence of a constant $\mathrm{O}_{2}$ flux $\left(\mathrm{O}_{2}\right.$ test $\left.-\mathrm{F}_{\mathrm{O} 2}=7 \mathrm{NL} / \mathrm{h}\right)$ and in the presence of a constant $\mathrm{N}_{2}$ flux $\left(\mathrm{F}_{\mathrm{N} 2}=7 \mathrm{NL} / \mathrm{h}\right)$. The latter case comprehended two different oxygen starvation tests: PFOA degradation under $\mathrm{N}_{2}$ flux with an air-saturated initial solution $\left(N_{2}\right.$ test $)$ and with a $\mathrm{N}_{2}$-presaturated reaction environment $\left(N_{2 s a t}\right.$ test - PFOA solution fluxed with $\mathrm{N}_{2}$ for $12 \mathrm{~h}$ until saturation, then $\mathrm{F}_{\mathrm{N} 2}=$ $7 \mathrm{NL} / \mathrm{h}$ during the kinetic test). Dark and photolysis tests were also conducted (Table S.I.9 and Table S.I.10, respectively).

In order to verify the deactivating effect of fluoride ions towards $\mathrm{TiO}_{2}$, an additional test $(F$ test $)$ was performed by adding potassium fluoride $\left([\mathrm{KF}]_{0}=120 \mathrm{mM}\right)$ to the initial PFOA solution. In these conditions PFOA photoabatement was not observed, thus confirming the effects due to the fluoride-promoted deactivation of the catalyst (see Table S.I.11 in the Supporting Information for more details).

\subsection{Detection of carbonyl difluoride}

The intent of this test was the detection of $\mathrm{COF}_{2}$, hypothesized as a specific by-product in the PFOA degradation pathway based on the $\beta$-scission reaction. The photocatalytic apparatus described in Paragraph 3.2 was connected to an on-line Thermo Nicolet 380 FT-IR set with a PTFE 
gas-tight IR cell (volume $8 \mathrm{~cm}^{3}$, length $10 \mathrm{~cm}$ ) equipped with $\mathrm{CaF}_{2}$ windows. The outlet gases of the cell were neutralized in a saturated $\mathrm{NaHCO}_{3}$ aqueous solution. PFOA $\left([\mathrm{PFOA}]_{0}=4 \mathrm{mM}\right)$ was dissolved in a high boiling point PFPE-based solvent (Galden ${ }^{\circledR}$ HT-170) and this solution was introduced in the reactor. The use of aqueous solutions in the photoabatement of PFOA did not allow the detection of $\mathrm{COF}_{2}$ because of its rapid hydrolysis. Titanium dioxide P-25 (0.66 g/L) was used as a photocatalyst and the UV lamp $\left(75 \mathrm{~W} / \mathrm{m}^{2}\right)$ was placed beside the reactor. Oxygen $\left(\mathrm{F}_{\mathrm{O} 2}=7\right.$ $\mathrm{NL} / \mathrm{h}$ ) was continuously fluxed in the reactor. FT-IR analysis was used to monitor the composition of the outlet gases and to verify the formation of $\mathrm{COF}_{2}$, by comparing its typical IR signal at 1928 $\mathrm{cm}^{-1}$ due to the $\mathrm{C}=\mathrm{O}$ stretching (Table S.I.12). The concentration of $\mathrm{COF}_{2}$ (expressed in parts per million by volume, ppmV) was calculated on the basis of its reported molar absorptivity at 10110 $\mathrm{cm} / \mathrm{mmol}$ [42]. A portion of the outlet gases was bubbled in a NMR tube containing toluene- $d_{8}$ cooled in a dry ice-acetone bath at $-78^{\circ} \mathrm{C}[52] .{ }^{19} \mathrm{~F}-\mathrm{NMR}$ spectrum was recorded on a Bruker 500 Ultrashield spectrometer operating at $470.30 \mathrm{MHz}$ and $305 \mathrm{~K}$.

Chemical stability test of pure Galden ${ }^{\circledR}$ HT-170 towards UV-activated $\mathrm{TiO}_{2}$ and dark test of a PFOA solution in Galden ${ }^{\circledR}$ HT-170 were also performed under $\mathrm{O}_{2}$ flux $\left(\mathrm{F}_{\mathrm{O} 2}=7 \mathrm{NL} / \mathrm{h}\right.$ - see Tables S.I.13 and S.I.14 in the Supporting Information for more details).

\subsection{TOC analysis and ion chromatography}

Total Organic Carbon (TOC) analysis allowed to evaluate and to monitor the trend of the carbon content of the solution. TOC analyses were performed with a Shimadzu ${ }^{\circledR}$ TOC 5000 A with a combustion/non-dispersive infrared (NDIR) gas analysis method. The total organic carbon concentration of the PFOA solution at different photodegradation times was calculated automatically by comparing the sample with a calibration curve obtained from PFOA solutions at defined concentrations. In the kinetic study of PFOA degradation, the data obtained by TOC analysis were considered for the calculation of $\mathrm{C} / \mathrm{C}_{0}$ ratios. The PFOA degradation generated 
fluoride ions in solution and their concentration was monitored by Ion Chromatography (IC) with a Metrohm 883 Basic IC Plus.

\subsection{High-Performance Liquid Chromatography with Mass Spectrometry (HPLC-MS)}

Analytes separation was performed by using an Agilent 1100 Series HPLC Value System, consisting of a quaternary pump, vacuum degasser and auto sampler. The instrument was equipped with a Lichrocart ${ }^{\circledR}$ 55-4 Purospher $^{\circledR}$ STAR RP-18 end capped column (55 x $4.0 \mathrm{~mm}$ i.d., $\left.3 \mu \mathrm{m}\right)$ supplied by Merck KGaA. For quantitative determination, the chromatographic system was interfaced to a Bruker Esquire 3000 Plus quadrupole ion trap mass spectrometer (Bruker Daltonics) operating in negative electrospray mode. Instrumental parameters were optimized to transmit the $[\mathrm{M}-\mathrm{H}]^{-}$ions for all expected degradation intermediates. Primary ions monitored for PFOA, perfluoroheptanoic acid (PFHpA), perfluorohexanoic acid (PFHxA), perfluoropentanoic acid (PFPeA), perfluorobutanoic acid (PFBA), perfluoropropionic acid (PFPrA) and trifluoroacetic acid (TFA) determinations were 413, 363, 313, 263, 213, 163 and 113 [M-H]', respectively (see Appendix A). Samples of the reaction mixture collected at different reaction times were diluted in deionized water $(1: 10)$ and injected in the HPLC-MS with $2 \mathrm{mM}$ ammonium acetate/methanol as the mobile phase starting at $10 \%$ methanol, at a flow rate of $200 \mu \mathrm{L} / \mathrm{min}$. The gradient increased to $90 \%$ methanol at $5 \mathrm{~min}$; before reverting to original conditions at $20 \mathrm{~min}$, the gradient decreased to $80 \%$ methanol at $15 \mathrm{~min}$. Column temperature was maintained at $40^{\circ} \mathrm{C}$. HPLC-MS spectrum of $\mathrm{Air}$ Test sample collected after $7 \mathrm{~h}$ and the extractions of primary ions due to PFOA and degradation PFCA intermediates are reported as example in the Supporting Information (Fig. S.I.1).

\subsection{Fluorine-19 nuclear magnetic resonance $\left({ }^{19}\right.$ F-NMR) spectroscopy}

${ }^{19}$ F-NMR tests were performed on a Bruker 500 Ultrashield spectrometer operating at $470.30 \mathrm{MHz}$ and $305 \mathrm{~K}$, in order to evaluate the trend of PFOA signals. In particular, for each kinetic test, the samples of solution collected from the photoabatement reactor at the beginning and at different 
specific times were analyzed by ${ }^{19} \mathrm{~F}-\mathrm{NMR}$, using $\mathrm{D}_{2} \mathrm{O}$ as solvent. PFOA integral calculation allowed the detection of degradation products by considering the ratio between the integrals of the peaks ascribable to $\mathrm{CF}_{3}$ groups, present in all the degradation by-products $\left(\mathrm{C}_{2}-\mathrm{C}_{7}\right.$ perfluorinated acids; see Appendix A) and the integrals of the peaks ascribable to $\mathrm{CF}_{2}$ signals.

\subsection{X-ray photoelectron spectroscopy (XPS)}

X-ray photoelectron spectroscopy spectra were obtained by using an M-probe apparatus (Surface Science Instruments). The source was monochromatic Al Ka radiation (1486.6 eV). A spot size of $200 \mu \mathrm{m} \times 750 \mu \mathrm{m}$ and pass energy of $30 \mathrm{eV}$ were used. $1 s$ level hydrocarbon-contaminant carbon was taken as the internal reference at $284.6 \mathrm{eV}$. Fittings were performed by using pure Gaussian peaks, Shirley's baseline, and without any constraints. X-ray photoelectron spectroscopy analysis was performed to study the composition of the photocatalyst surface after the photodegradation of a PFOA solution in Galden ${ }^{\circledR}$ HT-170. The $\mathrm{TiO}_{2}$ sample for XPS analysis was obtained by centrifuging and filtering through a $0.45 \mu \mathrm{m}$ polycarbonate membrane the surfactant solution at the end of the reaction $(15 \mathrm{~h})$; the sample was then dried in inert atmosphere for 24 hours and analyzed. High resolution XPS analyses in the typical zone of C $1 s$ (as reference) and Ti $2 p$ were performed.

\section{Results and discussion}

\subsection{Photocatalytic oxidation of perfluorooctanoic acid}

The solubility of perfluorocarboxylic acids can be approximated to their critical micelle concentration (CMC). In particular, PFOA is characterized by a CMC of $0.0078 \mathrm{M}$ and above this value PFOA molecules tend to aggregate in micelles of average dimension around $100 \mathrm{~nm}$, originating a colloid [48]. Below the CMC, PFOA molecules are expected to exhibit lower chemical stability than PFOA aggregates towards the coupled effect of $\mathrm{TiO}_{2}$ and UV light [28]. On the basis of the optimizations achieved in previous studies [27,28], the general experimental conditions were maintained by setting PFOA initial concentration at $0.0040 \mathrm{M}\left([\mathrm{PFOA}]_{0}<\mathrm{CMC}\right), \mathrm{TiO}_{2}$ content at 
$0.66 \mathrm{~g} / \mathrm{L}$ and UV-lamp power at $75 \mathrm{~W} / \mathrm{m}^{2}$. Different kinetic tests were realized in order to evaluate the effects of oxygen excess or defect in the reaction environment. PFOA degradation trends were monitored in static conditions with atmospheric concentration of $\mathrm{O}_{2}($ Air test $)$ and in the presence of a constant $\mathrm{O}_{2}$ flux $\left(\mathrm{O}_{2}\right.$ test $\left.-\mathrm{F}_{\mathrm{O} 2}=7 \mathrm{NL} / \mathrm{h}\right)$ in order to obtain an $\mathrm{O}_{2}$-enriched environment. Two kinetic tests were also run under $\mathrm{N}_{2}$ flux in $\mathrm{O}_{2}$ starvation conditions, either in the presence of residual oxygen traces due to the air-saturated initial solution $\left(N_{2}\right.$ test $)$ or in the complete absence of $\mathrm{O}_{2}$ obtained by pre-saturating the PFOA solution with $\mathrm{N}_{2}$ before starting the photocatalytic experiment ( $N_{2 s a t}$ test - see Paragraph 2.2 for details). The surfactant abatement trends were evaluated by monitoring at different times the mineralization percentage of the treated solutions by TOC analysis, the fluoride contents by IC analysis (Tables S.I.1, S.I.3, S.I.5 and S.I.7) and the degradation intermediates concentrations by HPLC-MS (Tables S.I.2, S.I.4, S.I.6 and S.I.8). PFOA concentrations expressed as ppm of carbon ascribed to PFOA and measured by HPLC-MS were reported for benchmarking purposes with the experimental TOC concentrations (Fig. 1-A). PFOA degradation kinetic data were interpolated by pseudo-first order curves $\left(\mathrm{R}^{2}>0.96\right)$ which enabled the comparison of the apparent rate constants, $k_{\text {app }}$ (Fig. 1-B).
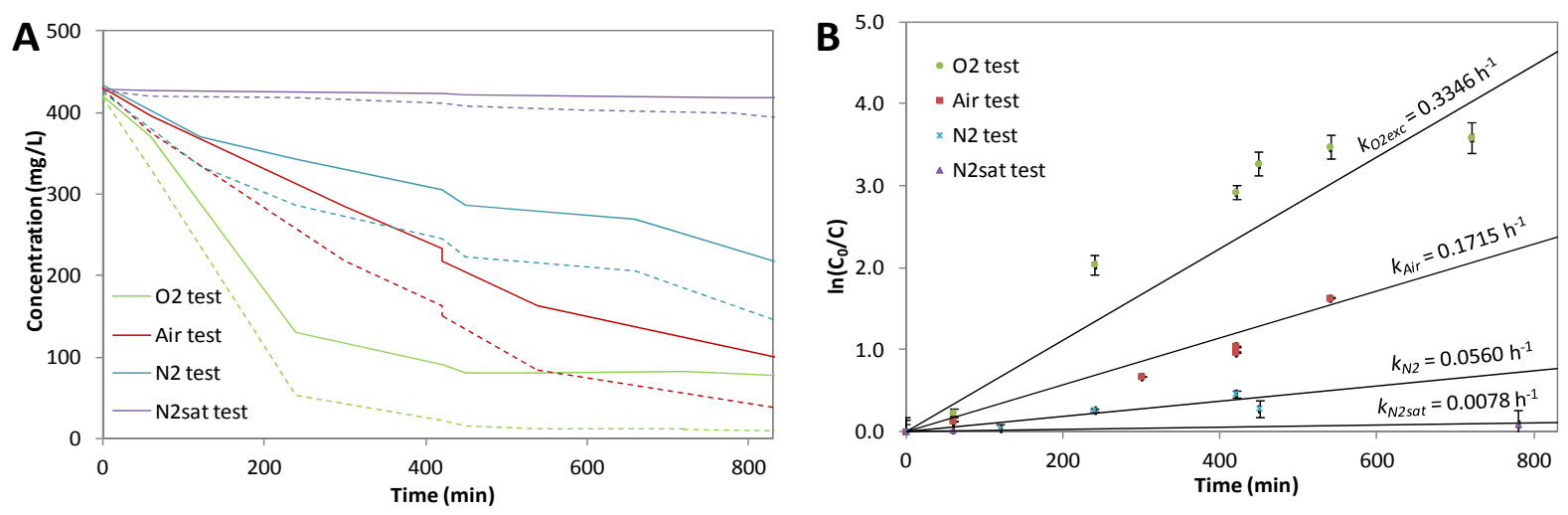

Figure 1. Concentration trends of TOC data (solid lines) compared to the ppm of carbon corresponding to PFOA concentration monitored by HPLC-MS (dashed lines) for the different kinetic tests $\left(\mathrm{O}_{2}, \mathrm{Air}, \mathrm{N}_{2}\right.$ and $\mathrm{N}_{2 \text { sat }}$ test $)$ (A); linearization of PFOA degradation data obtained in the different kinetic tests $\left(\mathrm{O}_{2}, \mathrm{Air}, \mathrm{N}_{2}\right.$ and $\mathrm{N}_{2 s a t}$ test $)(\mathrm{B})$. 
In the Air test, TOC content and PFOA concentration resulted to be constantly decreasing along the whole experiment and a substantially constant gap can be observed (Fig. 1-A). Considering the $\mathrm{O}_{2}$ test, the total mineralization was very rapid during the first $4 \mathrm{~h}$ of abatement and after $7 \mathrm{~h}$ PFOA appeared to be almost completely degraded: $[\mathrm{PFOA}]_{7 \mathrm{~h}} /[\mathrm{PFOA}]_{0}=0.034$. After $4 \mathrm{~h}$, the mineralization rate clearly decreased, probably due to the $\mathrm{F}^{-}$-promoted chemical modifications of the catalyst surface [27]. The gap between the trends of TOC content and PFOA degradation was substantially constant after $7 \mathrm{~h}$. The $N_{2 \text { sat }}$ test was run in $\mathrm{N}_{2}$ pre-saturated reaction environment and a very low decrease in the TOC content was observed (Fig. 1-A): at the end of the test mineralization was slightly higher than $2 \%$. Differently, the residual oxygen content present in the $N_{2}$ test due to the air-saturated initial solution raised the final mineralization to more than $50 \%$ and the PFOA abatement was about $71 \%$ (Fig. 1-A). These results are in complete agreement with the expected behavior of the system by supporting the enhancing role of oxygen in the reaction mechanism of PFOA photodegradation.

The linearization of PFOA degradation data are reported in Figure 1-B for all the experimental conditions tested, along with the calculated apparent kinetic constant. The apparent kinetic constant obtained in the $O_{2}$ test $\left(k_{O 2}=0.3346 \mathrm{~h}^{-1}\right)$ was almost twice the one calculated in the Air test $\left(k_{\text {Air }}=\right.$ $\left.0.1715 \mathrm{~h}^{-1}\right)$ (Fig.1-B). As expected, tests run in the presence of $\mathrm{O}_{2}$ starvation $\left(N_{2}\right.$ test and $N_{2 s a t}$ test $)$ allowed lower rates of PFOA removal $\left(k_{N 2}=0.0560 \mathrm{~h}^{-1}, k_{N 2 s a t}=0.0078 \mathrm{~h}^{-1}\right)$. From the comparison of the calculated $k_{\text {app }}$, the importance of working in $\mathrm{O}_{2}$-enriched conditions during PFOA photodegradation was confirmed. Moreover, no PFOA abatement was observed by working in the presence of $\mathrm{TiO}_{2}$ as photocatalyst $(0.66 \mathrm{~g} / \mathrm{L})$ without UV irradiation (dark test, Table S.I.9) or by working just under UV irradiation $\left(75 \mathrm{~W} / \mathrm{m}^{2}\right)$ without photocatalyst (photolysis test, Table S.I.10), in accordance to the literature [24]. The absence of any PFOA abatement in the dark test confirmed also that PFOA adsorption on the $\mathrm{TiO}_{2}$ surface was negligible.

PFOA degradation intermediates were identified and quantified by HPLC-MS analysis. In the Air test, the concentration trends of the degradation intermediates in solution followed a well-defined 
order: the higher the molecular weight of the intermediate, the higher its presence in solution $($ PFHpA $>$ PFHxA $>$ PFPeA $>$ PFBA $>$ PFPrA $>$ TFA) (Fig. 2-A and 2-B). PFHpA concentration increased up to a maximum value $(0.632 \mathrm{mM})$ followed by an evident decrease. This concentration trend can be related to the $\mathrm{C}_{\mathrm{n}} \rightarrow \mathrm{C}_{\mathrm{n}-1}$ chain length degradation pathway. It is important to notice that the shorter-chain acids formation during PFOA decomposition observed at the beginning of the reaction and the presence of TFA and PFPrA after 30 minutes (Fig. 2-B) cannot be ascribed to the generally accepted photo-redox consecutive $C_{n} \rightarrow C_{n-1}$ chain length decrease mechanism [29]. These findings can be justified by an alternative decomposition mechanism based on the elimination of $\mathrm{COF}_{2}$ as a decomposition product induced by $\beta$-scission reactions of oxyradicals, in competition with the stepwise chain length decrease [28]. Overall, the concentration trends of PFOA degradation intermediates represented an indirect proof of the coexistence of two degradation pathways. In the $\mathrm{O}_{2}$ test, PFHpA maximum concentration was comparable with the one observed in the Air test, as well as the final concentrations of PFHxA and PFPeA (Fig. 2-C and 2D). On the contrary, PFPrA and TFA were definitely more concentrated at the end of the $\mathrm{O}_{2}$ test than in the Air test. In the presence of $\mathrm{O}_{2}$ excess, PFOA decrease appeared to be definitely more rapid and higher concentrations of short chain acids were detected. These results suggested that a PFOA oxidation mechanism alternative to the $C_{n} \rightarrow C_{n-1}$ stepwise chain length degradation should be considered, especially in the presence of appreciable $\mathrm{O}_{2}$ concentrations. In the $N_{2}$ test (Fig. 2-E and 2-F), the formation of shorter-chain acids resulted greatly limited: $[\mathrm{PFPrA}]_{\max }$ and $[\mathrm{TFA}]_{\max }$ were 0.008 and $0.002 \mathrm{mM}$, respectively. In fact, in $\mathrm{O}_{2}$ starvation, the PFOA abatement appeared to follow the generally accepted stepwise $C_{n} \rightarrow C_{n-1}$ chain length decrease mechanism and the PFOA concentration decreased constantly with gradual increase in $\mathrm{C}_{7}-\mathrm{C}_{6}$ acids content and relatively low formation of shorter chain acids. In $N_{2 s a t}$ test, the very limited PFOA abatement (Fig. 1) and the related small increase in the PFOA degradation intermediates concentrations (Fig. 2-G and 2-H) were probably due to traces of oxidant species in the solution ascribable to residual $\mathrm{O}_{2}$ or to the reaction between photogenerated holes and water adsorbed onto $\mathrm{TiO}_{2}$ particles [53]. These 
evidences overall suggest that the use of an external source of oxygen can promote the PFOA degradation.
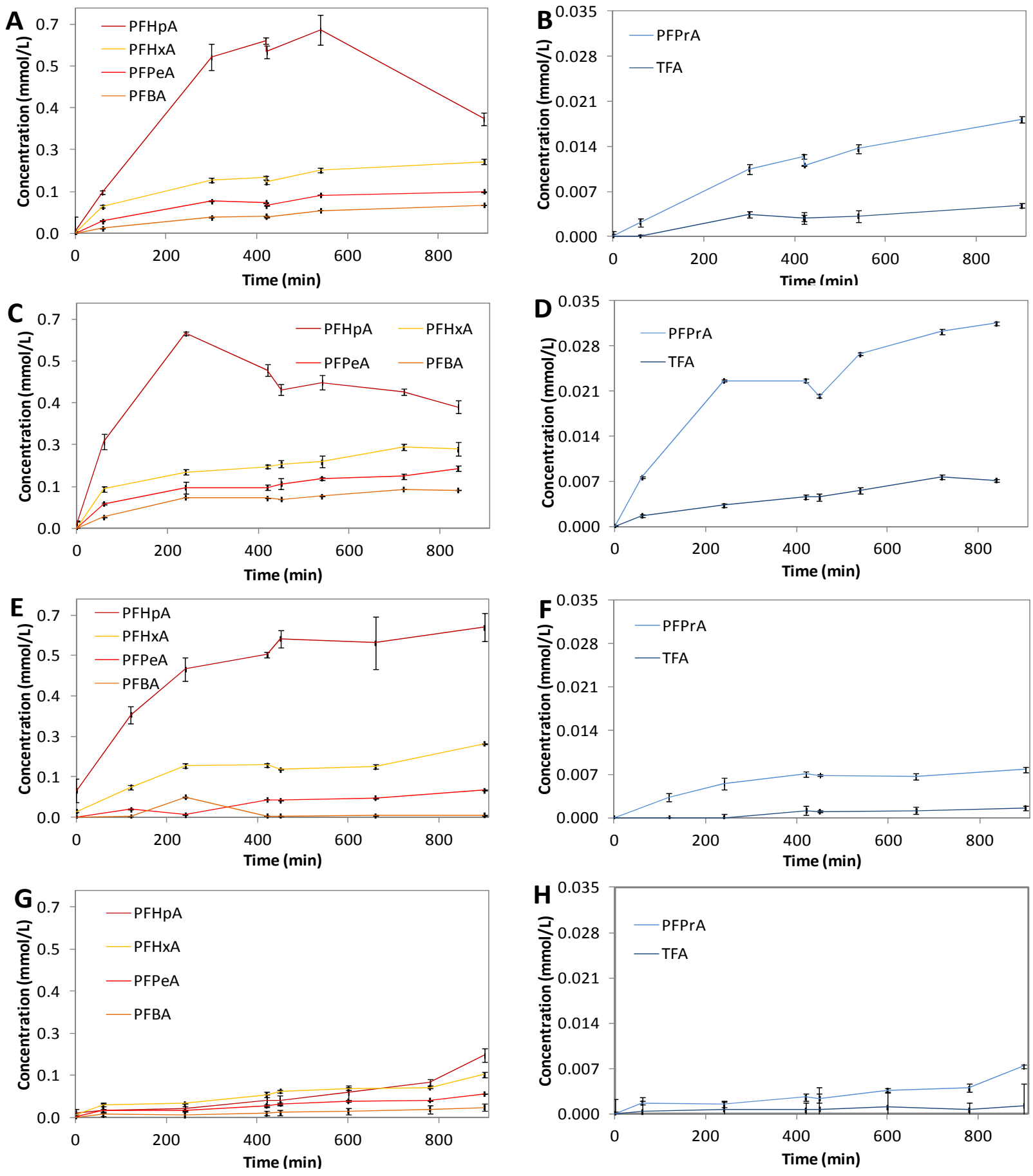

Figure 2. Concentration trends of PFOA degradation intermediates (PFHpA, PFHxA, PFPeA, PFBA, PFPrA, TFA) in Air test (A, B), in $O_{2}$ test $(\mathrm{C}, \mathrm{D}), N_{2}$ test $(\mathrm{E}, \mathrm{F})$ and $N_{2 \text { sat }}$ test $(\mathrm{G}, \mathrm{H})$. 
PFOA degradation is expected to produce fluoride ions due to several routes such as dehydrofluorination of primary perfluorinated alcohols and hydrolysis of both $\mathrm{COF}_{2}$ and perfluoroacyl fluoride intermediates. Overall, fluoride release can be considered as a complementary marker of PFOA mineralization; however, differences in the balance between fluoride yields and mineralization degrees can be noticed and should be ascribed to several contributory causes, such as the volatility of some PFOA decomposition products, like HF and $\mathrm{COF}_{2}$, the partial fluorination of the $\mathrm{TiO}_{2}$ catalyst and the undesired production of $\mathrm{SiF}_{6}{ }^{=}$. Fluoride concentration in solution increased linearly during the Air test until around $9 \mathrm{~h}$ of photoabatement; then $\mathrm{F}^{-}$increase was less pronounced (Fig. S.I.2-B). At the end of the treatment, the detected fluoride concentration was $29 \mathrm{mM}$, corresponding to a $\mathrm{F}^{-}$yield of $48 \%$. Fluoride release in $\mathrm{O}_{2}$ test was definitely quicker than in the case of Air test (Fig. S.I.3-B): the $\mathrm{F}^{-}$concentration reached 25 $\mathrm{mM}$ after $4 \mathrm{~h}$ which was about 2.5 times the $\mathrm{F}^{-}$content observed in the Air test after the same degradation time $(10 \mathrm{mM}$ after $4 \mathrm{~h})$; after $7 \mathrm{~h}$ treatment, the $\mathrm{F}^{-}$concentration reached a plateau and a maximum value of $31 \mathrm{mM}$, slightly higher than the one in the Air test. This trend can be ascribed to an almost complete deactivation of the catalyst due to the chemical interactions of fluoride ions with $\mathrm{TiO}_{2}$ surface moieties [27,28]. In $N_{2}$ test as well as in $N_{2 s a t}$ test, a limited fluoride release was observed (Fig. S.I.4-B and S.I.5-B): at the end of the tests (after 15 h), [F-] were about 6 and $3 \mathrm{mM}$, respectively; $\mathrm{F}^{-}$yields were around $10 \%$ and $5 \%$, respectively. These results confirm that the photocatalytic degradation of fluorinated surfactants in solution is significantly influenced by the presence of dissolved oxygen.

\section{3. ${ }^{19} F-N M R$ results}

Referring to the labeled formula $\mathrm{CF}_{3(\eta)} \mathrm{CF}_{2(\zeta)} \mathrm{CF}_{2(\varepsilon)} \mathrm{CF}_{2(\delta)} \mathrm{CF}_{2(\gamma)} \mathrm{CF}_{2(\beta)} \mathrm{CF}_{2(\alpha)} \mathrm{COOH}$, the assignments of PFOA in the ${ }^{19}$ F-NMR spectra (Fig. S.I.6) were in agreement with literature: $\delta=-81.9\left(3 \mathrm{~F}, \mathrm{~F}_{\eta}\right)$, $-127.1\left(2 \mathrm{~F}, \mathrm{~F}_{\zeta}\right),-123.8\left(2 \mathrm{~F}, \mathrm{~F}_{\varepsilon}\right),-123.1\left(2 \mathrm{~F}, \mathrm{~F}_{\delta}\right),-122.9\left(2 \mathrm{~F}, \mathrm{~F}_{\gamma}\right),-124.2\left(2 \mathrm{~F}, \mathrm{~F}_{\beta}\right),-118.5\left(2 \mathrm{~F}, \mathrm{~F}_{\alpha}\right)$ ppm [52,53]. The peaks of shorter perfluorinated acids $\left(\mathrm{C}_{7-3}\right)$ have chemical shifts located in the 
immediate vicinity of PFOA signals, except for trifluoroacetic acid (TFA) that is characterized by a single signal at $-76.55 \mathrm{ppm}$ (generally used as a calibration standard) $[28,54,55] .{ }^{19} \mathrm{~F}-\mathrm{NMR}$ spectra of PFOA solutions collected from the photoabatement reactor at different times during the kinetic tests (Air, $\mathrm{O}_{2}, \mathrm{~N}_{2 s a t}$ and $\mathrm{N}_{2}$ tests) were recorded in order to confirm the variation in the chemical composition of the samples. The integrals of the signals ascribable to $\mathrm{CF}_{2(\alpha-\zeta)}$ and $\mathrm{CF}_{3(\eta)}$ were calculated for each spectra and the corresponding ratios $(\vartheta)$ between the sum of $\mathrm{CF}_{2(\alpha-\zeta)}{ }^{19} \mathrm{~F}-\mathrm{NMR}$ integrals and the sum of $\mathrm{CF}_{3(\eta)}$ integrals were also evaluated (Table 1): $\vartheta=\sum\left(\mathrm{CF}_{2(\alpha-\zeta)}\right.$ integrals $) / \sum\left(\mathrm{CF}_{3(\eta)}\right.$ integrals). The direct mineralization of PFOA (Eq. 2) progressively reduces the concentrate of the starting acid, formally avoiding the formation of shorter chain species and maintaining constant the ratio $\vartheta$ :

$$
\mathrm{CF}_{3}\left(\mathrm{CF}_{2}\right)_{6} \mathrm{COOH}+7 / 2 \mathrm{O}_{2}+7 \mathrm{H}_{2} \mathrm{O} \rightarrow 8 \mathrm{CO}_{2}+15 \mathrm{HF}
$$

On the contrary, if the PFOA decomposition proceeds across intermediates, shorter chain acids are generated and the ${ }^{19} \mathrm{~F}-\mathrm{NMR}$ integrals ascribable to $\mathrm{CF}_{2}$ moieties in the chains decrease independently from the terminal $\mathrm{CF}_{3}$ integrals; thus, the ratio $\vartheta$ is expected to decrease.

Table 1. Comparison of $\vartheta$ values at different decomposition time for Air, $\mathrm{O}_{2}, \mathrm{~N}_{2}$ and $\mathrm{N}_{2 \text { sat }}$ kinetic tests.

\begin{tabular}{lccc}
\hline Test & $\begin{array}{c}\text { Time } \\
(\mathbf{h})\end{array}$ & $\begin{array}{c}\mathbf{9} \\
\mathbf{( - )}\end{array}$ & $\begin{array}{c}\text { Mineralization } \\
(\mathbf{\%})^{\mathbf{a}}\end{array}$ \\
\hline Air test & 0 & 4.0 & 0 \\
& 7 & 3.7 & 50 \\
& 9 & 2.9 & 62 \\
O $_{2}$ test & 15 & 1.6 & 80 \\
& 0 & 4.0 & 0 \\
$N_{2}$ test & 4 & 3.3 & 69 \\
& 7 & 2.3 & 78 \\
& 0 & 4.0 & 0 \\
$N_{2 s a t}$ test & 7 & 3.9 & 30 \\
& 15 & 3.3 & 54 \\
& 0 & 4.0 & 0 \\
a. \% mineralization calculated on the basis of TOC data. & 1 \\
\hline
\end{tabular}


As reported in Table 1 , the calculated $\vartheta$ value in the starting solution was equal to 4.0 . The comparison of $\vartheta$ values at similar mineralization degrees in different tests reveals the relative incidence of the two alternative degradation pathways: in particular, low $\vartheta$ values can be ascribed to a higher influence of the photo-redox $C_{n} \rightarrow C_{n-1}$ stepwise mechanism; conversely, experiments characterized by high $\vartheta$ values preferably follow the $\beta$-scission pathway. In Air and $\mathrm{O}_{2}$ tests, the comparison of $\vartheta$ values highlighted a well-defined trend; in fact at similar mineralization degrees, $\vartheta_{\text {Air }}$ were always significantly lower than $\vartheta_{\mathrm{O} 2}$ (Table 1): at mineralization of $62 \%, \vartheta_{\text {Air }}$ at 9 h was equal to 2.9 , while $\vartheta_{\mathrm{O} 2}$ at $4 \mathrm{~h}$ was 3.3 ; more markedly, at mineralization of $80 \% \vartheta_{\text {Air }}$ at $15 \mathrm{~h}$ was equal to 1.6, that is definitely lower than $2.3\left(\vartheta_{\mathrm{O} 2}\right.$ at $\left.7 \mathrm{~h}\right)$. A similar trend was observed in Air and $N_{2}$ tests: at mineralization of $52 \%, \vartheta_{\text {Air }}$ at $7 \mathrm{~h}$ was found equal to 3.7 while $\vartheta_{\mathrm{N} 2}$ at $15 \mathrm{~h}$ was 3.3 .
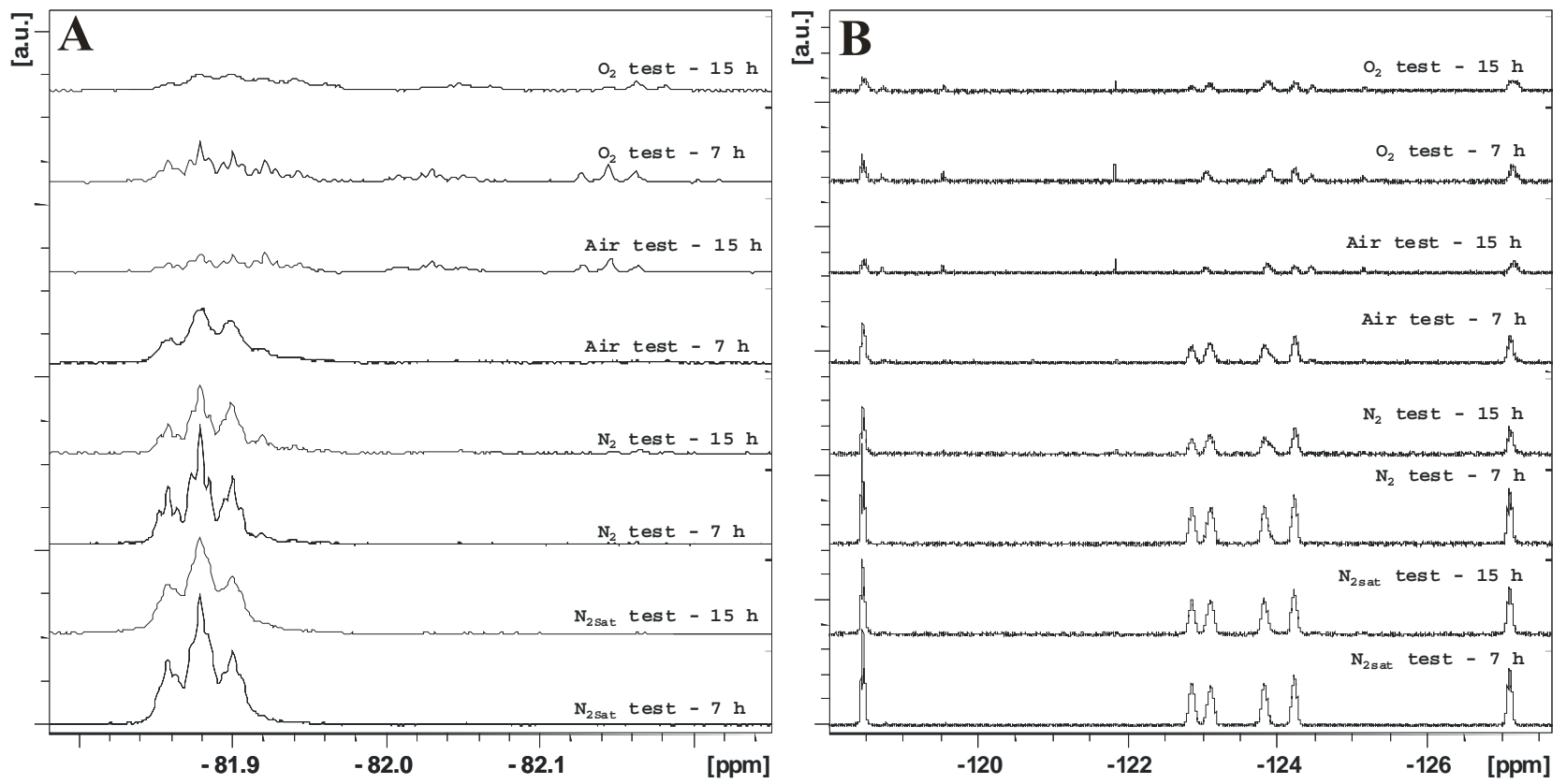

Figure 3. Comparison of ${ }^{19} \mathrm{~F}-\mathrm{NMR}$ spectra recorded at 7 and $15 \mathrm{~h}$ for $\mathrm{Air}, \mathrm{O}_{2}, \mathrm{~N}_{2 \text { sat }}$ and $\mathrm{N}_{2}$ kinetic tests: zooms in the $\mathrm{CF}_{3(\eta)}(\mathrm{A})$ and $\mathrm{CF}_{2(\alpha-\zeta)}(\mathrm{B})$ regions.

On the basis of these results it is possible to hypothesize that in the presence of a constant $\mathrm{O}_{2}$ feed $\left(\mathrm{O}_{2}\right.$ test $)$ the degradation of PFOA preferentially follows the $\beta$-scission pathway. On the contrary, in $\mathrm{O}_{2}$ starvation conditions ( $N_{2}$ test), the photo-redox $\mathrm{C}_{\mathrm{n}} \rightarrow \mathrm{C}_{\mathrm{n}-1}$ chain length mechanism appears to be 
preponderant. In the case of PFOA degradation in the presence of naturally dissolved oxygen (Air test), a balanced coexistence of $\beta$-scission and photo-redox pathways is possible.

It is also interesting to compare the $\mathrm{CF}_{3(\eta)}$ signals obtained at different PFOA mineralization (Fig. 3A). In the spectra of Air test at $15 \mathrm{~h}$ and $\mathrm{O}_{2}$ test at both 7 and $15 \mathrm{~h}$, the well-resolved triplet of triplets of the PFOA $\mathrm{CF}_{3(\eta)}$ signal at $-81.86 \mathrm{ppm}$ varied in multiple signals resulting from the partial overlapping of several contributions: a triplet at $-82.15 \mathrm{ppm}$ due to PFPrA, a triplet of triplets at -82.03 ppm due to PFPeA and a multiplet in the range between -81.86 and $-81.92 \mathrm{ppm}$ due to overlapping triplets of triplets ascribable to PFOA, PFHpA, PFHxA and PFBA [55-61]. This transition confirmed the coexistence of comparable amounts of different perfluorocarboxylic acids $\left(\mathrm{C}_{8-3}\right)$. In addition, the presence of TFA $\left(\mathrm{C}_{2}\right)$ was also proved by its distinctive signal at $-76.55 \mathrm{ppm}$ (Fig. S.I.7-11). Conversely, in the spectra of $N_{2}$ and $N_{2 s a t}$ tests at both 7 and $15 \mathrm{~h}$, the $\mathrm{CF}_{3(\eta)}$ signal of PFOA remained almost unchanged (Fig. S.I.12 and S.I.13); in $N_{2}$ test at $15 \mathrm{~h}$ a slight shoulder at $81.92 \mathrm{ppm}$ can be detected. Comparatively, in these tests it was possible to notice a complementary trend in the $\mathrm{CF}_{2(\alpha-\zeta)}$ signals (from -118 to $-128 \mathrm{ppm}$ ) obtained at different PFOA mineralization (Fig 3-B): in the spectra of Air test at $15 \mathrm{~h}$ and $\mathrm{O}_{2}$ test at both 7 and $15 \mathrm{~h}, \mathrm{CF}_{2}$ signals almost disappeared and new weak $\mathrm{CF}_{2}$ signals appeared at -118.7 (triplet; $\mathrm{CF}_{2(\alpha)}$ of PFBA), -119.5 (quartet; $\mathrm{CF}_{2(\alpha)}$ of PFPrA), -124.5 (multiplet; $\mathrm{CF}_{2(\beta)}$ of PFPeA) and -125.2 ppm (multiplet; $\mathrm{CF}_{2(\beta)}$ of PFBA), ascribable to low concentration of shorter perfluorocarboxylic acids [55-61]. In $N_{2}$ test at $15 \mathrm{~h}$ and in Air test at $7 \mathrm{~h}$, only a broadening of the intense signal of the $\mathrm{CF}_{2(\alpha-\zeta)}$ peaks was observed.

\section{3. $\beta$-scission of perfluorooxyradicals and carbonyl difluoride detection}

The PFOA degradation passes through the formation of oxygen-centered perfluororadicals, as already reported in the literature [28]. The commonly accepted mechanisms foresee that these radicalic intermediates evolve by producing unstable perfluorinated alcohols, which further decompose to perfluoroacyl fluorides by eliminating hydrofluoric acid [65]. However, the $\beta$ scission reaction of perfluorinated oxyradicals $\left(\mathrm{C}_{n} \mathrm{O}\right)$ is thermodynamically favored with a low 
kinetic barrier; shorter carbon-centered perfluoroalkyl radicals $\left(\mathrm{C}_{\mathrm{n}-1}\right)$ and $\mathrm{COF}_{2}$ are formed as reaction products [18]. Perfluoroalkyl radicals continue the degradation pathway and $\mathrm{COF}_{2}$ is rapidly hydrolyzed in aqueous media by generating $\mathrm{CO}_{2}$ and $\mathrm{HF}$. To demonstrate this pathway, the hydrolysis of $\mathrm{COF}_{2}$ should be inhibited by setting the experiment in the absence of water and allowing the release of $\mathrm{COF}_{2}$ from the reaction environment in gaseous phase. Therefore, a specific test was defined in order to achieve the PFOA degradation in absence of water and to avoid the $\mathrm{COF}_{2}$ hydrolysis. A high boiling point perfluoropolyether $\left(\right.$ Galden ${ }^{\circledR} \mathrm{HT}-170$, b.p. $\left.=170^{\circ} \mathrm{C}\right)$ was chosen as a solvent because of its solvating properties on PFOA $(\sim 1,9 \mathrm{~g} / \mathrm{L})$, inertness to radicals, stability towards UV-light and low volatility. The remaining experimental parameters of the test were maintained consistent with the $\mathrm{O}_{2}$ test by setting PFOA initial concentration at $4 \mathrm{mM}, \mathrm{TiO}_{2}$ content at $0.66 \mathrm{~g} / \mathrm{L}$, UV-lamp power at $75 \mathrm{~W} / \mathrm{m}^{2}$ and oxygen flux at $7 \mathrm{NL} / \mathrm{h}$. Oxygen was continuously fluxed in the reactor in order to enhance the concentration of perfluorinated peroxyradicals and consequently to facilitate the formation of $\mathrm{COF}_{2}$. As soon as the PFOA photocatalytic oxidation in the perfluoropolyether solvent started, the outlet gases from the reactor were analyzed by FT-IR spectroscopy and the production of $\mathrm{COF}_{2}$ was monitored (Fig. 4 and Table S.I.12). The typical IR pattern of $\mathrm{COF}_{2}$ with the intense signal at $1928 \mathrm{~cm}^{-1}$ due to the $\mathrm{C}=\mathrm{O}$ stretching was easily recognized in the spectra (Fig. S.I.14) [42]. The IR signals of $\mathrm{CO}_{2}$ antisymmetrical stretching at $2350 \mathrm{~cm}^{-1}$ and $\mathrm{HF}$ lines in the range $3700-4200 \mathrm{~cm}^{-1}$ were also present. A portion of the outlet gases was also analyzed by ${ }^{19} \mathrm{~F}-\mathrm{NMR}$ spectroscopy and the spectrum revealed an evident signal at $-21.5 \mathrm{ppm}$ ascribable to $\mathrm{COF}_{2}$ (Fig. S.I.15) [52]. While the concentration trends of PFOA degradation intermediates indirectly suggest the existence of two competitive degradation pathways, the detection of $\mathrm{COF}_{2}$ can be considered as a direct experimental evidence of the $\beta$-scissions route in the PFOA degradation mechanism. 


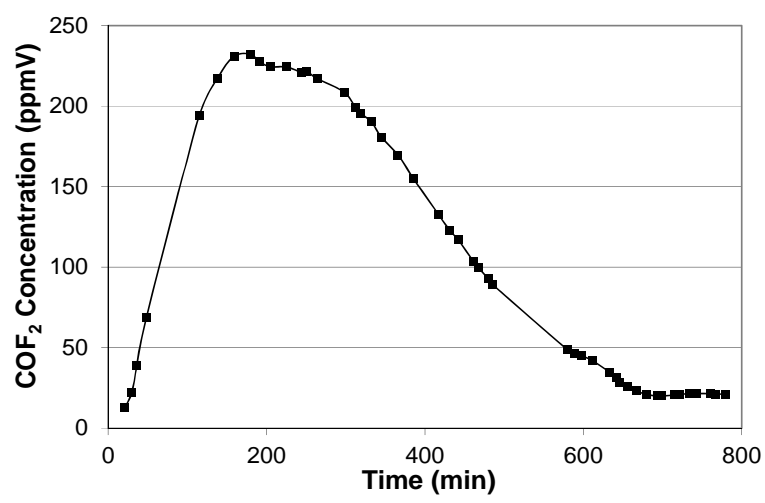

Figure 4. $\mathrm{COF}_{2}$ concentration (expressed as parts per million by volume, ppmV) in outlet gases during the decomposition of PFOA dissolved in a high boiling point PFPE-based solvent (Galden ${ }^{\circledR}$ HT-170).

In the PFPE-solvent PFOA was completely degraded after approximately $12 \mathrm{~h}$ and the maximum $\mathrm{COF}_{2}$ concentration in the flux resulted equal to $232 \mathrm{ppmV}$. The $\mathrm{COF}_{2}$ concentration trend over time revealed the rapid and almost complete decomposition of the PFOA through the $\beta$-scission pathway (Fig. 4). In addition, the production of $\mathrm{COF}_{2}$ and its removal from the reaction environment, due to stripping action by the oxygen flow, reduced the release of fluoride ions in the solution. Thus, $\mathrm{TiO}_{2}$ deactivation due to fluoride ions was inhibited by performing PFOA photooxidation in a PFPE-based solvent and, even after $15 \mathrm{~h}$ of photoabatement only a minor part of the catalyst turned out to be fluorinated. At the end of the test, XPS analysis of $\mathrm{TiO}_{2}$ catalyst (Fig. S.I.16) showed in the Ti $2 p$ region two couples of peaks which can be attributed to pure titanium dioxide (at 458-464 eV) and to titanium fluorides with low fluorination degree (at 460-466 $\mathrm{eV}$ ). On the basis of the deconvolutions, the amount of these fluorinated species was estimated as $30 \%$ of the surface composition.

\subsection{Suggested mechanism for PFOA photocatalytic oxidation}

The experimental results discussed in this work allowed new insights on the PFOA degradation mechanism. In particular, the role of oxygen, the concentration trends of the degradation 
intermediates and the detection of $\mathrm{COF}_{2}$ offer a new interpretation of the photocatalytic oxidation of PFOA.

It is commonly recognized that the PFOA degradation mechanism is initiated with the excitation of titanium dioxide caused by the irradiation of UV light $[29,36,66]$; after being excited by UV radiation (Fig. 5 - Reaction a), $\mathrm{TiO}_{2}$ accepts one electron from dissociated PFOA in water $\left(\mathrm{CF}_{3}\left(\mathrm{CF}_{2}\right)_{6} \mathrm{COO}^{-}\right)$, generating PFOA radical (Fig. 5 - Reaction b) $[29,36,66]$. As clarified by various papers, PFOA decomposition starts in correspondence to the carboxylic function that undergoes a Kolbe decarboxylation (Fig. 5 - Reaction c) [29,67-69].

$$
\begin{gathered}
\mathrm{TiO}_{2} \stackrel{h v}{\rightarrow} \mathrm{TiO}_{2}^{*}\left(\mathrm{~h}^{+}+\mathrm{e}^{-}\right) \\
\mathrm{CF}_{3}\left(\mathrm{CF}_{2}\right)_{6} \mathrm{COO}^{-} \stackrel{h^{+}}{\rightarrow} \mathrm{CF}_{3}\left(\mathrm{CF}_{2}\right)_{6} \mathrm{COO} . \\
\mathrm{CF}_{3}\left(\mathrm{CF}_{2}\right)_{6} \mathrm{COO} \cdot \rightarrow \mathrm{CF}_{3}\left(\mathrm{CF}_{2}\right)_{5} \mathrm{CF}_{2} \cdot+\mathrm{CO}_{2}
\end{gathered}
$$

The energetically favoured reaction of $\mathrm{C}_{7}$ radicals includes the formation of primary perfluorinated alcohols by coupling with hydroxyl radicals produced by water oxidation due to photo-generated holes $\left(\mathrm{Ti}^{\mathrm{IV}} \mathrm{OH}^{+}\right)($Fig. 5 - Reaction d) [70]:

$$
\mathrm{CF}_{3}\left(\mathrm{CF}_{2}\right)_{5} \mathrm{CF}_{2} \cdot+\mathrm{OH} \cdot \rightarrow \mathrm{CF}_{3}\left(\mathrm{CF}_{2}\right)_{5} \mathrm{CF}_{2} \mathrm{OH}
$$

However, as demonstrated by the kinetic tests, a high concentration of oxygen in the reaction environment promotes the coupling between $\mathrm{C}_{7}$ radicals and $\mathrm{O}_{2}$ by inducing the formation of peroxyradicals (Fig. 5 - Reaction e) [71]:

$$
\mathrm{CF}_{3}\left(\mathrm{CF}_{2}\right)_{5} \mathrm{CF}_{2} \cdot+\mathrm{O}_{2} \rightarrow \mathrm{CF}_{3}\left(\mathrm{CF}_{2}\right)_{5} \mathrm{CF}_{2} \mathrm{OO}
$$

The coupling of two peroxyradicals allows the production of oxyradicals (Fig. 5 - Reaction f) that, in the presence of the surface excited electrons of $\mathrm{TiO}_{2}$ and water, generate an unstable primary perfluorinated alcohol (Fig. 5 - Reaction g) [71,72].

$$
\begin{aligned}
& 2 \mathrm{CF}_{3}\left(\mathrm{CF}_{2}\right)_{5} \mathrm{CF}_{2} \mathrm{OO} \cdot 2 \mathrm{CF}_{3}\left(\mathrm{CF}_{2}\right)_{5} \mathrm{CF}_{2} \mathrm{O} \cdot+\mathrm{O}_{2} \\
& \mathrm{CF}_{3}\left(\mathrm{CF}_{2}\right)_{5} \mathrm{CF}_{2} \mathrm{O} \cdot+\mathrm{H}_{2} \mathrm{O} \stackrel{e^{-}}{\rightarrow} \mathrm{CF}_{3}\left(\mathrm{CF}_{2}\right)_{5} \mathrm{CF}_{2} \mathrm{OH}+\mathrm{OH}^{-}
\end{aligned}
$$


Alternatively, peroxyradicals can react with molecular oxygen originating oxyradicals and releasing ozone that can react with $C_{7}$ radicals, generating further oxyradicals [18].

Primary perfluorinated alcohols produced in reactions (d) and (g) are widely reported as thermodynamically unstable (from -80 to $-160 \mathrm{~kJ} / \mathrm{mol}$ ) and originate the corresponding acyl fluorides and hydrogen fluoride (Fig. 5 - Reaction h) [68,72]; in the presence of water, the acyl fluorides hydrolyze to carboxylic acids (Fig. 5 - Reaction i) [72-75].

$$
\begin{aligned}
& \mathrm{CF}_{3}\left(\mathrm{CF}_{2}\right)_{5} \mathrm{CF}_{2} \mathrm{OH} \rightarrow \mathrm{CF}_{3}\left(\mathrm{CF}_{2}\right)_{5} \mathrm{C}(\mathrm{O}) \mathrm{F}+\mathrm{HF} \\
& \mathrm{CF}_{3}\left(\mathrm{CF}_{2}\right)_{5} \mathrm{C}(\mathrm{O}) \mathrm{F}+\mathrm{H}_{2} \mathrm{O} \rightarrow \mathrm{CF}_{3}\left(\mathrm{CF}_{2}\right)_{5} \mathrm{COOH}+\mathrm{HF}
\end{aligned}
$$

The reactions from (a) to (i) are at the basis of the stepwise $C_{n} \rightarrow C_{n-1}$ chain length shortening during PFOA degradation. The evidences obtained from the concentration trends of the degradation intermediates and the detection of $\mathrm{COF}_{2}$ prove the existence of another reaction pathway, where the oxyradical formed in reaction (f) evolves by eliminating $\mathrm{COF}_{2}$ through monomolecular $\beta$-scission and consequent generation of a $\mathrm{C}_{\mathrm{n}-1}$ radical $[4,76,77]$ :

$$
\mathrm{CF}_{3}\left(\mathrm{CF}_{2}\right)_{5} \mathrm{CF}_{2} \mathrm{O} \cdot \rightarrow \mathrm{CF}_{3}\left(\mathrm{CF}_{2}\right)_{4} \mathrm{CF}_{2} \cdot+\mathrm{COF}_{2}
$$

The carbon-centered perfluorinated radical is redirected at the step of reaction (e), while fluorophosgene is quenched in the aqueous environment generating hydrogen fluoride and carbon dioxide [72]. It is remarkable that the mechanism based on $\beta$-scissions can promote an almost complete PFOA decomposition without the formation of perfluorinated acids as intermediates. Thus, the key steps of the complete oxidation mechanism are represented by the two competing reactions: the bimolecular reduction of the oxyradical activated by $\mathrm{TiO}_{2}$ surface (Fig. 5 - Reaction g) and the monomolecular $\beta$-scission generating $\mathrm{COF}_{2}$ and $\mathrm{C}_{\mathrm{n}-1}$ radical (Fig. 5 - Reaction $\mathrm{j}$ ). 


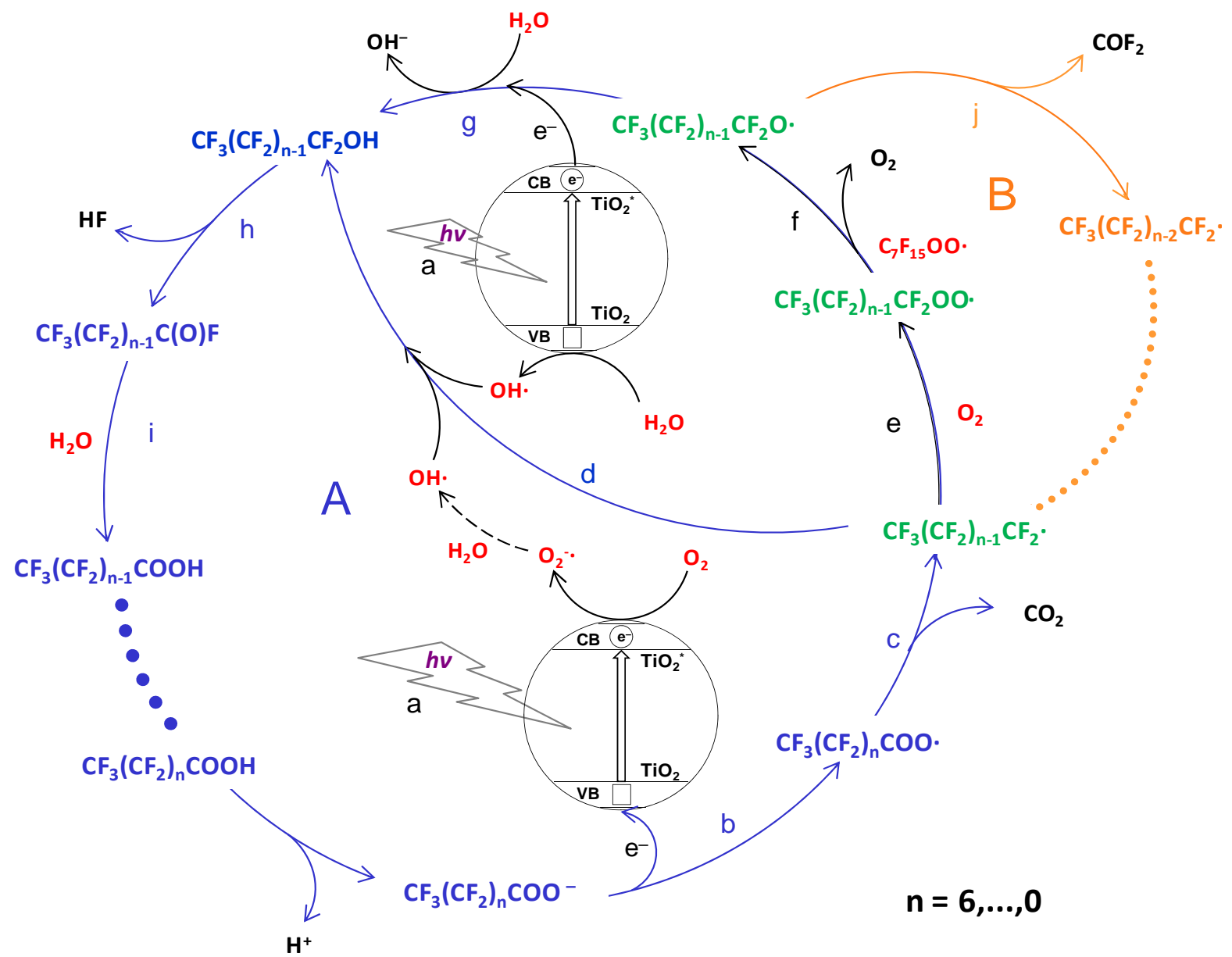

Figure 5. Reaction mechanism of PFOA degradation in the presence of $\mathrm{TiO}_{2}$ photocatalyst: photoredox pathway (A - blue arrows); $\beta$-scission pathway (B - orange arrows).

\section{Conclusions}

The photocatalytic oxidation of PFOA promoted by titanium dioxide was studied by testing the reaction in different conditions: static air, oxygen flux, nitrogen flux and pre-saturated nitrogen flux. The effects of oxygen excess or defect in the reaction environment were evaluated in different kinetic tests by measuring mineralization degrees and fluoride releases by TOC analysis and IC, respectively. Concentration trends of PFOA degradation intermediates were also determined by HPLC-MS and ${ }^{19}$ F-NMR analyses. In particular, the disclosure of very short chain acids at the beginning of the reaction suggested the presence a PFOA oxidation mechanism alternative to the stepwise photo-redox $C_{n} \rightarrow C_{n-1}$ pathway: the $\beta$-scissions routes mediated by $\mathrm{COF}_{2}$ elimination. The mechanism based on $\beta$-scission reactions appeared to be dominant in $\mathrm{O}_{2}$-enriched solutions, 
while in $\mathrm{O}_{2}$-starving conditions the photo-redox $\mathrm{C}_{n} \rightarrow \mathrm{C}_{n-1}$ chain length decrease mechanism prevailed. These hypotheses were confirmed by detecting carbonyl difluoride, $\mathrm{COF}_{2}$, specifically produced in the $\beta$-scission pathway. An appropriate kinetic test was set for $\mathrm{COF}_{2}$ detection by avoiding its easy hydrolysis and a high boiling point perfluoropolyether as reaction solvent was employed because of the solvating properties on PFOA. Thus, $\mathrm{COF}_{2}$ production was characterized by ${ }^{19} \mathrm{~F}-\mathrm{NMR}$ and IR analyses. The production of $\mathrm{COF}_{2}$ in a non-aqueous medium also reduced the release of fluoride ions in the reaction environment and hindered the $\mathrm{F}^{-}$-induced catalyst deactivation. In addition to the confirmation of the mechanism, it is worth to notice that carbonyl difluoride is an important industrial intermediate and its synthesis with good selectivity and high purity was possible starting from PFOA as pioneering recycling of this banned fluorinated surfactant.

\section{Appendix A. Glossary of acronyms, names (classical and IUPAC) and condensed chemical formulas for PFCAs}

PFOA Perflurooctanoic acid (or perfluorocaprylic acid)

$\mathrm{CF}_{3}\left(\mathrm{CF}_{2}\right)_{6} \mathrm{COOH}$

\section{2,2,3,3,4,4,5,5, 6,6, 7, 7,8,8,8-Pentadecafluorooctanoic acid}

PHpA Perfluroheptanoic acid (or perfluoroenhantic acid)

$\mathrm{CF}_{3}\left(\mathrm{CF}_{2}\right)_{5} \mathrm{COOH}$

\section{2,2,3,3,4,4,5,5, 6,6, 7, 7,7-Tridecafluoroheptanoic acid}

PFHxA Perflurohexanoic acid (or perfluorocaproic acid)

$\mathrm{CF}_{3}\left(\mathrm{CF}_{2}\right)_{4} \mathrm{COOH}$

\section{2,2,3,3,4,4,5,5,6,6,6-Undecafluorohexanoic acid}

PFPeA Perfluropentanoic acid (or perfluorovalerianic acid)

$\mathrm{CF}_{3}\left(\mathrm{CF}_{2}\right)_{3} \mathrm{COOH}$

\section{2,2,3,3,4,4,5,5,5-Nonafluoropentanoic acid}

PFBA Perflurobutanoic acid (or perfluorobutyric acid)

$\mathrm{CF}_{3}\left(\mathrm{CF}_{2}\right)_{2} \mathrm{COOH}$

\section{2,2,3,3,4,4,4-Heptafluorobutanoic acid}

PFPrA Perfluropropanoic acid (or perfluoropropionic acid)

$\mathrm{CF}_{3} \mathrm{CF}_{2} \mathrm{COOH}$

\section{2,2,3,3,3-Pentafluoropropanoic acid}




\section{2,2,2-Trifluoroethanoic acid}

\section{Acknowledgments}

The authors wish to acknowledge with thanks the generous support and the valuable interactions induced to this research in the field of fluorinated materials by the institution of the Politecnico di Milano/Solvay Fluorine Chemistry Chair. This work has been supported by MIUR (PRIN 20102011, prot. 2010PFLRJR).

\section{References}

[1] J. G. Drobny, Technology of Fluoropolymer, second ed., CRC Press, Boca Raton, 2009.

[2] W. Navarrini, M. V. Diamanti, M. Sansotera, F. Persico, M. Wu, L. Magagnin, S. Radice, Prog. Org. Coat. 74 (2012) 794-800.

[3] F. Persico, M. Sansotera, C. L. Bianchi, C. Cavallotti, W. Navarrini, Appl. Catal., B 170 (2015) 83-89.

[4] M. Avataneo, W. Navarrini, U. De Patto, G. Marchionni, J. Fluorine Chem. 130 (2009) 933937.

[5] C. Cornelis, W. D’Hollander, L. Roosens, A. Covaci, R. Smolders, R. Van den Heuvel, E. Govarts, K. Van Campenhout, H. Reynders, L. Bervoets, Chemosphere 86 (2012) 308-314.

[6] J. H. Johansson, U. Berger, R. Vestergren, I. T. Cousins, A. Bignert, A. Glynn, P. O. Darnerud, Environ. Pollut. 188 (2014) 102-108.

[7] R. C. Buck, J. Franklin, U. Berger, J. M. Conder, I. T. Cousins, P. de Voogt, A. A. Jensen, K. Kannan, S. A. Mabury, S. P. J. van Leeuwen, Integr. Environ. Assess. Manag. 7 (2011) 513-541.

[8] E. Smulders, W. Von Rybinski, A. Nordskog, Laundry Detergents. Ullmann's Encyclopedia of Industrial Chemistry, seventh ed., Wiley-VCH, Weinheim, 2011.

[9] C. A. Moody, J. A. Field, Environ. Sci. Technol. 34 (2000) 3864-3870. 
[10] A. Singh, J. D. Van Hamme, O. P. Ward, Biotechnol. Adv. 25 (2007) 99-121.

[11] G. Kostov, F. Boschet, B. Ameduri, J. Fluorine Chem. 130 (2009) 1192-1199.

[12] G. Boutevin, D. Tiffes, C. Loubat, B. Boutevin, B. Ameduri, J. Fluorine Chem. 134 (2012) 7784.

[13] G. Marchionni, V. Tortelli, I. Wlassics, V. Kapeliouchko, US 8703889 B2 (2014).

[14] M. A. Guerra, K. Hintzer, M. Jurgens, H. Kaspar, A. R. Maurer, G. I. Moore, Z. M. Qiu, J. F. Schulz, W. Schwertfeger, T. Zipplies, US 0276103 A1 (2007).

[15] T. Ishikawa, N. Tsuda, Y. Yamamoto, US 7777075 B2 (2010).

[16] J. Hoshikawa, S. Higuchi, Y. Matsuoka, N. Yamagishi US 7709566 B2 (2010).

[17] P. D. Brothers, S. V. Gangal US 7932333 B2 (2011).

[18] J. Niu, H. Lin, C. Gong, X. Sun, Environ. Sci. Technol. 47 (2013) 14341-14349.

[19] S. M. Mitchell, M. Ahmad, A. L. Teel, R. J. Watts, Environ. Sci. Technol. Lett. 1 (2014) 117121.

[20] J. C. Lin, S. L. Lo, C. Y. Hub, Y. C. Lee, J. Kuo, Ultrason. Sonochem. 22 (2015) 542-547.

[21] N. Takeuchi, Y. Kitagawa, A. Kosugi, K. Tachibana, H. Obo, K. Yasuoka, J. Phys. D: Appl. Phys. 47 (2014) 045203.

[22] Y. Lee, S. Lo, J. Kuo, C. Hsieh, Front. Environ. Sci. Eng. 6 (2012) 17-25.

[23] W. Yuan, P. Zhang, J. Environ. Sci. 26 (2014) 2207-2214.

[24] R. R. Giri, H. Ozaki, T. Okada, S. Taniguchi, R. Takanami, Chem. Eng. J. 180 (2012) 197-203.

[25] M. J. Chen, S. L. Lo, Y. C. Lee, C. C. Huang, J. Hazard. Mater. 288 (2015) 168-175.

[26] B. Zhao, X. Li, L. Yang, F. Wang, J. Li, W. Xia, W. Li, L. Zhou, C. Zhao, Photochem. Photobiol. 91 (2015) 42-47.

[27] M. Sansotera, F. Persico, C. Pirola, W. Navarrini, A. Di Michele, C. L. Bianchi, Appl. Catal., B 148 (2014) 29-35.

[28] S. Gatto, M. Sansotera, F. Persico, M. Gola, C. Pirola, W. Panzeri, W. Navarrini, C. L. Bianchi, Catal. Today 241 (2015) 8-14. 
[29] S. C. Panchangam, A. Y. C. Lin, J. H. Tsai, C. F. Lin, Chemosphere 75 (2009) 654-660.

[30] C. D. Vecitis, H. Park, J. Cheng, B. T. Mader, M. R. Hoffmann, Front. Environ. Sci. Eng. China 3 (2009) 129-151.

[31] J. Liu, S. M. Avendaño, Environ. Int. 61 (2013) 98-114.

[32] Z. Wang, I. T. Cousins, M. Scheringer, K. Hungerbühler, Environ. Int. 60 (2013) 242-248.

[33] D. Friedmann, C. Mendive, D. Bahnemann, Appl. Catal., B 99 (2010) 398-406.

[34] O. Carp, C. L. Huisman, A. Reller, Prog. Solid State Chem. 32 (2004) 33-177.

[35] N. Serpone, J. Photochem. Photobiol. A 104 (1997) 1-12.

[36] A. Fujishima, T. N. Rao, D. A. Tryk, J. Photochem. Photobiol. C 1 (2000) 1-21.

[37] K. Sato, T. Hirakawa, A. Komano, S. Kishi, C. K. Nishimoto, N. Mera, M. Kugishima, T. Sanoa, H. Ichinose, N. Negishi, Y. Seto, K. Takeuchi, Appl. Catal., B 106 (2011) 316-322.

[38] S. R. Seagle in: J. I. Kroschwitz (Ed.), The Kirk-Othmer Encyclopedia of Chemical Technology, Vol. 24, fourth ed., John Wiley and Sons, New York, 1997, pp. 186-224.

[39] N. P. Mellott, C. Durucan, C. G. Pantano, M. Guglielmi, Thin Solid Films 502 (2006) 112-120.

[40] P. Pichat, in: E. Pelizzetti, N. Serpone (Eds.), Homogeneous and Heterogeneous Photocatalysis, Vol. 174, NATO ASI Series, Springer, New York/Heidelberg, 1986, pp. 533-554.

[41] J. Pacansky, R. J. Waltman, J. Phys. Chem. 95 (1991) 1512-1518.

[42] V. Francesco, M. Sansotera, W. Navarrini, J. Fluorine Chem. 155 (2013) 2-20.

[43] W. Navarrini, V. Tortelli, A. Russo, S. Corti, J. Fluorine Chem. 95 (1999) 27-39.

[44] W. Navarrini, A. Russo, V. Tortelli , J. Org. Chem. 60 (1995) 6441-6443.

[45] M. Sansotera, W. Navarrini, M. Gola, C. L. Bianchi, P. Wormald, A. Famulari, M. Avataneo, J. Fluorine Chem. 132 (2011) 1254-1261.

[46] W. Navarrini, C. L. Bianchi, L. Magagnin, L. Nobili, G. Carignano, P. Metrangolo, G. Resnati, M. Sansotera, Diam. Relat. Mater. 19 (2010) 336-341. 
[47] U. Järnberg, K. Holmström, B. van Bavel, A. Kärrman, Perfluoroalkylated acids and related compounds (PFAS) in the Swedish environment - Chemistry, Sources \& Exposure. Report to Swedish Environment Protection Agency (2006).

[48] C. Gambarotti, C. Punta, F. Recupero, T. Caronna, L. Palmisano, Curr. Org. Chem. 14 (2010) 1153-1169.

[49] S. Brosillon, L. Lhomme, C. Vallet, A. Bouzaza, D. Wolbert, Appl. Catal., B 78 (2008) 232241.

[50] J. B. Heredia, J. Torregrosa, J. R. Dominguez, J. A. Peres, J. Hazard. Mater. 83 (2001) 255264.

[51] P. Švec, A. Eisner, L. Kolářová, T. Weidlich, V. Pejchal, A. Růžička, Tetrahedron Lett. 49 (2008) 6320-6323.

[52] B. Ameduri, Chem. Rev. 109 (2009) 6632-6686.

[53] A. H. Karoyo, A. S. Borisov, L. D. Wilson, P. Hazendonk, J. Phys. Chem. B 115 (2011) 95119527.

[54] A. A. Ribeiro, J. Fluorine Chem. 83 (1997) 61-66.

[55] W. R. Dolbier, Guide to Fluorine NMR for Organic Chemists, Wiley, Hoboken, 2009.

[56] G. Filipovich, G. V. D. Tiers, J. Phys. Chem. 63 (1959) 761-763.

[57] D. O. Graham, W. B. McCormack, J. Org. Chem. 31 (1966) 958-959.

[58] C. Dapremont-Avignon, P. Calas, A. Commeyras, C. Amatore, J. Fluorine Chem. 51 (1991) 357-379.

[59] D. A. Ellis, K. A. Denkenberger, T. E. Burrow, S. A. Mabury, J. Phys. Chem. A 108 (2004) 10099-10106.

[60] A. A. Ribeiro, K. Umayahara, Magn. Reson. Chem. 41 (2003) 107-114.

[61] N. Ilayaraja, A. Manivel, D. Velayutham, M. Noel, J. Appl. Electrochem. 38 (2008) 175-186.

[62] Z. Liu, J. D. Goddard, J. Phys. Chem. A 113 (2009) 13921-13931. 
[63] R. D. Chambers in: R. D. Chambers (Ed.), Fluorine in Organic Chemistry, Blackwell Publishing Ltd., Oxford, 2004, pp. 236-295.

[64] A. Mills, S. Le Hunte, J. Photochem. Photobiol. A 108 (1997) 1-35.

[65] H. Hori, E. Hayakawa, H. Einaga, S. Kutsuna, K. Koike, T. Ibusuki, H. Kiatagawa, R. Arakawa, Environ. Sci. Technol. 38 (2004) 6118-6124.

[66] Y. Wang, P. Zhang, J. Hazard. Mater. 192 (2011) 1869-1875.

[67] H. Hori, A. Yamamoto, E. Hayakawa, S. Taniyasu, N. Yamashita, S. Kutsuna, Environ. Sci. Technol. 39 (2005) 2383-2388.

[68] C. Gong, X. Sun, C. Zhang, X. Zhang, J. Niu, Int. J. Mol. Sci. 15 (2014) 14153-14165.

[69] H. Lin, J. Niu, S. Ding, L. Zhang, Wat. Res. 46 (2012) 2281-2289.

[70] S. Kutsuna, H. Hori, Int. J. Chem. Kinet. 39 (2007) 276-288.

[71] C. Kormann, D. W. Bahnemann, M. R. Hoffmann, Environ. Sci. Technol. 25 (1991) 494-500.

[72] M. Sansotera, W. Navarrini, G. Resnati, P. Metrangolo, A. Famulari, C. L. Bianchi, P. A. Guarda, Carbon 48 (2010) 4382-4390.

[73] W. J. De Bruyn, J. A. Shorter, P. Davidovits, D. R. Worsnop, M. S. Zahniser, C. E. Kolb, Environ. Sci. Technol. 29 (1995) 1179-1185.

[74] A. M. B. Giessing, A. Feilberg, T. E. Mögelberg, J. Sehested, M. Bilde, T. J. Wallington, O. J. Nielsen, J. Phys. Chem. 100 (1996) 6572-6579.

[75] M. Sansotera, W. Navarrini, L. Magagnin, C. L. Bianchi, A. Sanguineti, P. Metrangolo, G. Resnati, J. Mater. Chem. 20 (2010) 8607-8616. 